\title{
PERAN GURU AGAMA ISLAM DALAM PEMBINAAN AKHLAQ REMAJA DI WILAYAH MAJLIS TA'LIM AL MUNAWWARAH CIBUBUR
}

\author{
Sidiq Sekar Ihsan \\ Akademi Pariwisata Jakarta \\ Email: sidiqihsan87@yahoo.com
}

\begin{abstract}
Abstrak
Kejahatan teknologi juga menjadi ancaman bagi para orang tua. Bagaimana tidak, dengan segala aspek perkembangan teknologi yang makin canggih sebuah harapan keluarga, harapan agama, harapan bangsa dan harapan Negara yaitu Remaja. Memiliki Akhlaq yang kurang baik, acuh tak acuh, dan bakti terhadap orang tua di abaikan. Di Saat ini Guru Agama Islam memiliki peran yang sangat besar, untuk mengawal remaja menjadi remaja yang berakhlaq baik dengan membentuk karakter pada diri remaja. Sebagai guru agama Islam di tuntut menjadi seorang guru yang bijaksana untuk mengajar dan membimbing. Oleh karena itu, melalui karya tulis ini, penulis berupaya melakukan pendekatan secara hati dan perbuatan, guna membentuk akhlaq remaja yang di harapkan keluarga, agama, bangsa dan negara. Cara tersebut dengan cara pengarahan, pelatihan, pembiasaan, pengawalan, wawancara, dan suri tauladan. Hal ini penting artinya bagi remaja dalam usaha menanamkan nilai akhlaq yang mulia. Guru agama Islam tidak hanya memberikan pelatihan saja, namun di iringi dengan perbuatan terhadap sesama makhluq Allah SWT, yaitu dengan memberikan santunan kepada yatim piatu dan dhu'afa. Terkait dengan hal ini, penulis melakukan studi kasus dan studi kepustakaan untuk merealisasikan peran guru agama Islam dalam pembinaan akhlaq remaja. Sehingga dapat menjadi solusi bagi guru dan pengoptimalisasi akhlaq di zaman teknologi dan mampu mempertahankan institusi keluarga sebagai miniatur masyarakat unggul.

Kata Kunci: Guru Agama Islam, Akhlaq Remaja
\end{abstract}

\begin{abstract}
The crime technology has been a threatening for the parents, however for all kind of aspects sophisticated tehnology development the teenagers are hopes for the family, the religion, the nation and the country. The religion's teachers have a big contribution when the teenagers have a bad morality, a perfunctory character and not royal to the parents. At present, Islamic's teachers have a big contribution to lead the teenagers to be a good morality and character, therefore as an Islamic's teachers are demanded to be a wise and to teach and to guide in creating their character. In this jurnal the writer has attempted to have an approach and an action to the teenagers in order to create a good expectation morality for the family, the religion, the nation and the country. Based on the problems above the some methods have been applied by the writer, such as directing, tranning, habituation, interview and a goodly pattern for the teenagers. Those methods are important to train them into a good morality. The religion teachers are not only give the training but also some good actions to Allah SWT's creatures for examples giving some charties to the orphaned and the poors. Likewise, the writer has applied the study case and library research to archieve the role of Islamic's teacher in guidance teenagers' morality so that, it is able to be a solution to the teachers and to reach a good morality's performance in technology era and able to defend the family's institution as a superior miniature society.
\end{abstract}

Keyword: Islamic Religion Teacher, Youth Behavior

PENDAHULUAN

Dizaman milenial ini perkembangan teknologi dan ilmu pengetahuan yang mudah diakses mengakibatkan terjadinya permasalahan pada kehidupan remaja [1] Dimana remaja mengalami perubahan fisik, 
psikis serta memiliki tingkat emosi yang tinggi. Remaja yang belum bisa mengontrol emosi dengan baik akan menyebabkan masalah yang ada dilingkungan sekitar. Salah satu masalah yang dilakukan remaja seperti pergaulan bebas, minuman keras, tidak peduli dengan keadaan lingkungan, dan berfoyafoya. Berdasarkan fenomena di atas, maka remaja perlu pembinaan. Pembinaan dapat dilakukan dilingkungan masyarakat, rumah dan BalaiWarga. Pembinaan dilingkungan remaja dapat dilakukan oleh guru agama Islam dengan cara pengarahan, pelatihan, pembiasaan, pengawalan, wawancara, dan suri tauladan dengan menyelenggarakan suatu kegiatan keagamaan misalnya pengajian yang bersifat rutin, bulanan, tahunan, silaturrahmi dan kegiatan bakti social.

Peran Guru Agama Islam dalam membina akhlaq remaja melalui kegiatan keagamaan di wilayah cibubur kecamatan ciracas Meliputi pelaksanaan kegiatan keagamaan dalam membina akhlaq remaja terdapat beberapa unsure yaitu pertama tujuan kegiatan keagamaan adalah membentuk akhlaq remaja menjadi lebih baik. Kedua tugas Pembina/ pendidik adalah untuk membimbing dan mengarahkan remaja agar memiliki akhlaq yang baik. Ketiga remaja mampu melaksanakan perintah Allah SWT dan menjauhi larangan Nya, keempat materi keagamaan. Kelima adanya metode keteladanan, pembiasaan, cerita/ kisah dan nasehat. Keenam peduli dengan keadaan lingkungan. Sedangkan factor pendukung dan penghambat yaitu factor pendukung yaitu keluarga, ustadz yang professional dan sumber dana. Kedua factor penghambat yaitu lingkungan pergaulan, masyarakat yang berpendidikan rendah, masyarakat yang kurang memperhatikan ketika pengajian dan sarana prasarana kurang memadai.

Dengan melihat fenomena di atas, maka jelas bahwa peran guru agama sangat di harapkan untuk pembentukan akhlaq di masyarakat khususnya di wilayah cibubur kecamatan ciracas, sebagaimana penulis wawancara ke Ketua Yayasan bahwa akhlaq seorang guru memiliki peran terhadap akhlaq remaja khusunya di wilayah cibubur kecamatan ciracas, sehingga menghasilkan sopan santun, menghormati yang besar, menyanyangi yang kecil, patuh kepada orang tua dan rasa ingin berbagi kepada yang membutuhkan.

Dengan melihat hasil wawancara diatas, maka jelas hal ini dapat dijadikan sebagai bahan suatu kesimpulan. Akan tetapi penulis ingin membuktikan secara ilmiah tentang peran seorang guru dalam meningkatkan akhlaq masyarakat di wilayah cibubur kecamatan ciracas.

\section{METODE}

Pada penelitian ini digunakan metodologi dengan pendekatan kualitatif. Yang mempunyai karakteristik alam (natural setting) sebagai sumber data langsung. Deskriptif proses lebih di pentingkan dari pada hasil. Analisis dalam penelitian kualitatif cenderung dilakukan secara analisa induktif serta makna merupakan hal yang esensial [2].

Terdapat 6 (enam) macam metodologi penelitian yang menggunakan pendekatan kualitatif, yakni etnografis, studi kasus grounden theory, interaktif, partisipatories, serta penelitian tindakan kelas [3]. Dalam hal ini penelitian yang digunakan yakni penelitian studi kasus (case study), yaitu suatu penelitian yang dilaksanakan untuk 
mempelajari secara intensif tentang latar belakang keadaan sekarang, serta interaksi lingkungan suatu unik sosial individual, kelompok, lembaga atau masyarakat.

Penelitian ini berlokasi di Balai Warga Rt. 005 / 009 tepatnya di jalan. Taruna Jaya Gg. VIII, Rt. 005 / 009 Kel. Cibubur Kec. Ciracas Jakarta Timur, DKI RAYA, 13720. Balai adalah gedung, rumah, kantor, Warga adalah anggota (keluarga, perkumpulan) [4]. Gedung tempat berkumpulnya warga antara rukun tetangga dan rukun tetangga yang lain, atau rukun warga dengan rukun warga lain untuk mengadakan musyawarah terkait kemaslahatan lingkungan itu sendiri. Tempat ini sering di gunakan oleh warga sekitar untuk kegiatan masyarakat, dari kegiatan antara rapat rukun tetangga dengan rukun tetangga ,rapat antara rukun warga dengan rukun warga, rapat karang taruna Remaja, rapat ibu - ibu PKK, rapat untuk hari - hari besar, kegiatan bakti sosial, pengajian dll.

Pada penelitian ini yang menjadi instrument utama adalah peneliti sendiri. Sumber data utama dalam penelitian ini yaitu, kata - kata, tindakan, selebihnya adalah tambahan seperti dokumen dan lainnya. Dengan demikian sumber data dalam penelitian ini berupa kata - kata dan tindakan sebagai sumber utama. Sedangkan sumber data tertulis. Foto dan catatan tertulis adalah sumber data tambahan.

\section{HASIL DAN PEMBAHASAN Agama Islam}

Agama Islam adalah agama yang dibawa oleh nabi Muhammad SAW, dengan agama inilah Allah SWT menutup agama - agama sebelumnya. Allah SWT telah menyempurnakan agama ini bagi hamba hamba Nya. Dengan agama Islam ini pula Allah Menyempurnakan ni'mat atas mereka.
Allah SWT hanya meridhoi Islam sebagai agama yang harus mereka peluk. [5] Oleh sebab itu tidak ada suatu agama pun yang diterima selain Agama Islam. Allah SWT berfirman dalam Al Qur'an Surat Al Ahzab: 40

Yang artinya: "Muhammad SAW itu bukanlah seorang ayah dari salah seorang lelaki diantara kalian, akan tetapi dia adalah utusan Allah SWT dan penutup para Nabi“‘(QS. Al Ahzab: 40). [6]

Di ayat lain pun menyebutkan di dalam QS. Al Maaidah : 3, artinya sebagai berikut : “ Pada hari ini Aku telah menyempurnakan bagi kalian agama kalian, dan Aku telah cukup kan ni'mat - ku atas kalian dan Aku pun telah Ridho Islam menjadi agama bagi kalian “. (QS. Al Maaidah: 3) [6]

Di ayat lain pun menyebutkan di dalam QS. Ali Imron: 19, artinya sebagai berikut: "Sesungguhnya Agama yang benar di sisi Allah SWT hanyalah Islam ". (QS. Ali Imron: 19). [6]

Di dalam shahih muslim terdapat sebuah hadist yang diriwayatkan kandari jalur abu hurairah radhiallahu 'anhu dari Rasulullah Shallallahu 'alaihiwassalam. Beliau bersabda yang artinya. "Demi zat yang jiwa Muhammad berada ditangannya. Tidaklah ada seorang manusia dari umat ini yang mendengar kenabianku, baik yang beragama yahudi maupun nasrani lantas dia meninggal dalam keadaan tidak mau beriman dengan jarang yang aku bawa melainkan dia pasti termasuk salah seorang penghuni neraka. “"

Hakikat beriman kepada nabi adalah denagn cara membenarkan apa yang beliau bawa dengan disertai sikap menerima dan patuh, bukan sekedar pembenaran saja. Oleh sebab itulah maka $\mathrm{Abu}$ thalib tidak bisa dianggap 
sebagai orang yang beriman terhadap Rasul Shallallahu 'alaihiwassalam, walaupun dia membenarkan ajaran yang beliau bawa, bahkan dia berani bersaksi bahwasannya Islam adalah agama yang terbaik. Agama Islam ini telah merangkum semua bentuk kemaslahatan yang diajarkan oleh agama agama sebelumnya. Agama Islam yang beliau bawa ini lebih istimewa dibandingkan agama - agama terdahulu karena Islam adalah ajaran yang bisa diajarkan dan di terapkan di setiap masa, disetiap tempat dan di masyarakat manapun. Allah SWT berfirman kepada Rasulullah shallallahu'alaihi wassalam [7].

Yang artinya: "dan kami telah menurunkan kepadamu Al Kitab dengan benar sebagai pembenar kitab - kitab yang terdahulu serta batu ujian atasnya. " (QS. Al Maaidah: 48) [6]

Maksud dari pernyataan Islam itu cocok diterapkan di setiap masa. Tempat dan masyarakat adalah dengan berpegang teguh dengannya tidak akan pernah bertentangan dengan kebaikan umat tersebut dimana kapan pun dan ditempat manapun. Bahkan dengan islamlah keadaan umat itu akan menjadi baik. Akan tetapi bukanlah yang dimaksud dengan pernyataan Islam itu cocok bagi setiap masa. Tempat dan masyarakat adalah Islam tunduk kepada kemauan setiap masa, tempat dan masyarakat, sebagai yang diinginkan oleh sebagian orang.

Agama Islam adalah agama yang benar. Sebuah agama yang telah mendapatkan jaminan pertolongan dan kemenangan dari Allah SWT bagi siapa saja yang berpegang teguh dengannya dengan sebenar - benarnya. Allah SWT berfirman, yang artinya [7].
"Dialah zat yang telah mengutus Rasul Nya dengan membawa petunjuk dan agama yang benar untuk di menangkan dia atas seluruh agama - agama yang ada, meskipun orang orang musyrik tidak menyukainya"(QS. Ash Shaf: 9) [6]

Agama islam adalah ajaran yang mencakup aqidah/ keyakinan dan syari'at/ hukum. Islam adalah ajaran yang sempurna, baik di tinjau dari sisi aqidah maupun syari'at syari'at yang diajarkannya: (1) Islam memerintahkan untuk mentauhidkan Allah WT dan melarang kesyirikan. (2) Islam memerintahkan untuk berbuat jujur dan melarang dusta. (3) Islam memerintahkan untuk berbuat adil dan melarang aniaya. (4) Islam memerintahkan untuk menuaikan amanat dan melarang berkhianat. (5) Islam memerintahkan untuk menepati janji dan melarang pelanggaran janji. (6) Islam memerintahkan untuk berbakti kepada orang tua dan melarang perbuatan durhaka kepada mereka. (7) Islam memerintahkan untuk menjalin silaturahim (hubungan kekerabatan yang terputus) dengan sanak famili dan islam melarang perbuatan memutuskan silaturahim. (8) Islam memerintahkan untuk berhubungan baik dengan tetangga dan melarang bersikap buruk kepada mereka [7].

Secara umum dapat dikatakan bahwasannya Islam memerintahkan semua akhlaq yang mulia dan melarang akhlaq yang rendah dan hina. Islam memerintahkan segala macam amal shalihan melarang segala amal yang jelak, Allah SWT berfirman, yang artinya: "Sesungguhnya Allah SWT memerintahkan berbuat adil, ihsan dan memberikan nafkah kepada sanak kerabat. Dan Allah SWT melarang semua bentuk perbuatan keji dan mungkar, serta tindakan melanggar batas, Allah SWT mengingatkan kalian agar kalian 
mau mengambil pelajaran. (QS. An Nahl: 90) [6]

\section{Akhlaq}

Agar lebih memahami apa definis akhlaq, maka kita dapat merujuk pada pendapat para ahli berikut ini:

\section{Abu Hamid Al Ghazali}

Menurut Abu Hamid Al Ghazali, pengertian akhlaq adalah suatu sifat yang tertanam dalam jiwa yang ada sejak lahir yang mana lahir perbuatan - perbuatan mudah tanpa memikirkannya.

\section{Muhammad Ali Asy Al Jurjani}

Menurut Muhammad Ali Asy Al Jurjani, pengertian akhlaq adalah suatu sifat yang terdiri dari sifat baik serta buruk yang ada sejak lahir dalam diri seseorang.

\section{Ahmad Bin Musthafa}

Menurut Ahmad Bin Musthafa, arti akhlaq adalah suatu ilmu yang dapat mengetahui keutamaan dan mengendalikan kekuatan dalam diri manusia, yaitu kekuatan berfikir, kekuatan syahwat dan kekuatan marah [7].

Dengan melihat dari pendapat para ahli, bahwa Akhlaq sudah ada pada jiwa setiap manusia, namun sekitarnya yang dapat mempengaruhinya. Ketika sekitarnya memiliki akhlaq yang baik secara otomatis akan mengikuti akhlaq yang baik, namun ketika di sekitarnya memiliki akhlaq yang kurang baik secara otomatis akan mengikuti akhlaq yang kurang baik. Jadi tergantung di sekitar lingkungan, lebih mengarah yang baik apa yang kurang baik. Dengan pendapat para ahli di atas maka penulis ingin mengadakan penelitian di wilayah majlis ta'lim al munawaarah cibubur.

\section{Penggolongan Akhlaq}

Akhlaq dapat digolongkan menjadi dua bagian, yaitu akhlaq terpuji dan akhlaq tercela. Mengacu pada pengertian akhlaq di atas, adapun penggolongan akhlaq adalah sebagai berikut:

\section{Akhlaq Terpuji}

Akhlaq Terpuji adalah sifat dan perilaku seseorang kepada orang lain yang dilakukan sesuai dengan norma-norma yang berlaku di amsyarakat. Beberapa yang termasuk dalam kategori akhlaq terpuji:

$\checkmark$ Sikap jujur : yaitu perilaku di dalam diri seseorang yang mau mengungkapkan sesuatu yang sebenarnya dengan tujuan tidak mendatangkan kerugian bagi dirinya dan orang lain

$\checkmark$ Perilaku baik: yaitu reaksi psikis seseorang dalam merespon hal - hal yang berada di sekitarnya dengan cara yang terpuji.

$\checkmark$ Rasa malu: yaitu bentuk emosi negatif di dalam diri seseorang sehingga membuat orang tersebut meninggalkan perbuatan perbuatan tercela yang dapat membuatnya malu.

$\checkmark$ Rendah hati: yaitu sifat pribadi seseorang yang selalu memposisikan dirinya sederajat dengan orang lain dan tidak merasa lebih tinggi dari orang lain.

$\checkmark$ Murah hati: yaitu sifat seseorang yang mudah memberi kepada orang lain tanpa ada keinginan untuk pamer atau pamrih.

$\checkmark$ Sabar: yaitu sifat di dalam diri seorang yang dapat bersikap bijak atau menahan diri dalam menyikapi segala sesuatu yang terjadi pada dirinya. [7]

\section{Akhlaq Tercela}

Akhlaq tercela adalah sifat dan perilaku seseorang kepada orang lain yang cenderung melanggar norma-norma yang berlaku di 
masyarakat. Beberapa yang termasuk dalam kategori akhlaq tercela adalah :

$\checkmark$ Suka mencuri: yaitu sifat dan perbuatan seseorang yang mengambil hak milik orang lain tanpa seizin dari pemiliknya.

$\checkmark$ Pemarah: sifat seseorang yang mudah marah ketika sesuatu tidak sesuai dengan keinginannya.

$\checkmark$ Pembohong: sifat seseorang yang suka berbohong kepada orang lain dengan tujuan tertentu

$\checkmark$ Fitnah: komunikasi kepada satu orang atau lebih yang bertujuan untuk memberikan stigma negative terhadap pihak lain berdasarkan atas fakta palsu yang dapat memengaruhi penghormatan, wibawa atau reputasi seseorang [7].

\section{Ruang Lingkup Akhlaq}

Secara umum ada lima hal yang termasuk di dalam ruang lingkup akhlaq seseorang di masyarakat:

1. Akhlaq pribadi: yaitu perilaku pribadi seseorang dalam menyikapi segala hal yang menyangkut dengan dirinya sendiri. Misalnya motivasi, etika, kreativitas, emosi dan lain sebagainya.

2. Akhlaq berkeluarga: yaitu perilaku seseorang dalam menyikapi hubungan dengan keluarganya meliputi kewajiban orang tua, anak dan kerabat. Misalnya etika kepada orang tua, tanggung jawab orang tua terhadap anak - anaknya, dan lain - lainnya.

3. Akhlaq bermasyarakat: yaitu perilaku seseorang dalam menyikapi hubungannya dengan anggota masyarakat yang ada di sekitarnya. Misalnya kehidupan masyarakat yang saling membantu, saling menghargai antar tetangga di sekitarnya dan lain sebagainya

4. Akhlaq bernegara: yaitu tingkah laku dan tindakan seseorang dalam menyikapi hubungannya dengan negara dan bangsanya. Misalnya membayar pajak demi pembangunan, menjaga kerukunan dan keutuhan bangsa dan lain sebagainya.

5. Akhlaq beragama: yaitu tingkah laku dan tindakan seseorang dalam melaksanakan kewajiban terhadap kepercayaanya, baik itu kepada Tuhan maupun kepada sesama manusia [7].

Setelah penulis mengkaji dari ruang lingkup akhlaq di atas, bahwa penelitian ini sesuai dengan yang di harapkan. Dari penelitian ini mengharapkan Remaja memiliki akhlaq terhadap dirinya sendiri, sopan santun terhadap kedua orang tua, di lingkungan saling menghormati, untuk menghasilkan Negara yang Rukun berlandasan Agama. Dengan akhlaq yang mulia remaja menerapkan rasa memiliki dengan cara saling membantu Yatim Piatu dan Dhu'afa di wilayah majlis ta'lim al munawwarah cibubur. Penulis semakin yakin, bahwa yang penulis teliti sesuai dengan ruang lingkup akhlaq dan berlandasan Al Qur'an. Sehingga penulis menjadi semangat memberikan materi tentang akhlaq dan melakukan kegiatan berbagi kepada yatim piatu dan dhu'afa.

Hasil penelitian dan pembahasan penelitian ini yaitu : 1) pendidikan agama islam dalam meningkatkan kualitas Akhlaq di wilayah majlis ta'lim Al Munawwarah Cibubur 2) Hambatan yang dialami dalam menghasilkan Akhlaq yang baik tidak hanya berasal dari remaja, namun juga dari pihak warga di wilayah majlis ta'lim Al Munawwarah Cibubur . Solusi untuk mengatasi hambatan tersebut adalah 1) Ketua Yayasan: kepada Ketua Yayasan diharapkan memonitoring remaja dari segi akhlaq di wilayah di majlis ta' lim Al Munawwarah Cibubur. 2) warga : warga diharapkan dapat memberikan contoh yang baik kepada Putra putrinya dengan berakhlaq dimana pun berada, memberikan 
penjelasan kepada putra putrinya dengan menjaga akhlaq dimanapun berada, memberikan semangat yang dapat dipahami, memberikan penjelasan kepada putra putrinya dengan alasan yang dapat dipahami dan diterima oleh putra putrinya.

Hasil penelitian dapat disimpulkan bahwa pembinaan akhlaq remaja melalui kegiatan keagamaan di wilayah cibubur kecamatan ciracas Meliputi pelaksanaan kegiatan keagamaan dalam membina akhlaq masyarakat terdapat beberapa unsure yaitu pertama tujuan kegiatan keagamaan adalah membentuk akhlaq masyarakat menjadi lebih baik. Kedua tugas pembina/ pendidik adalah untuk membimbing dan mengarahkan remaja agar memiliki akhlaq yang baik. Ketiga remaja mampu melaksanakan perintah Allah SWT dan menjauhi larangan Nya, keempat materi keagamaan. Kelima adanya metode keteladanan, pembiasaan, cerita/ kisah dan nasehat. Keenam peduli dengan keadaan lingkungan dengan cara berbagi kepada anak yatim dan dhu'afa di wilayah majlis ta'lim almunawwarah cibubur. Sedangkan factor pendukung dan penghambat yaitu factor pendukung yaitu keluarga, ustadz yang professional dan sumber dana. Kedua factor penghambat yaitu lingkungan pergaulan, masyarakat yang berpendidikan rendah, masyarakat yang kurang memperhatikan ketika pengajian dan sarana prasarana kurang memadai.

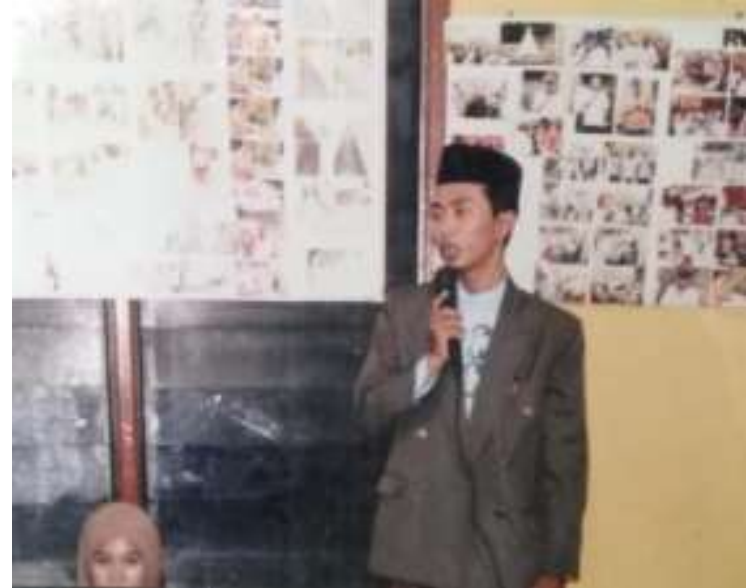

Gambar 1: Seorang Guru sedang menerangkan tentang tentang akhlaq dan fadilah berbagi kepada yang membutuhkan

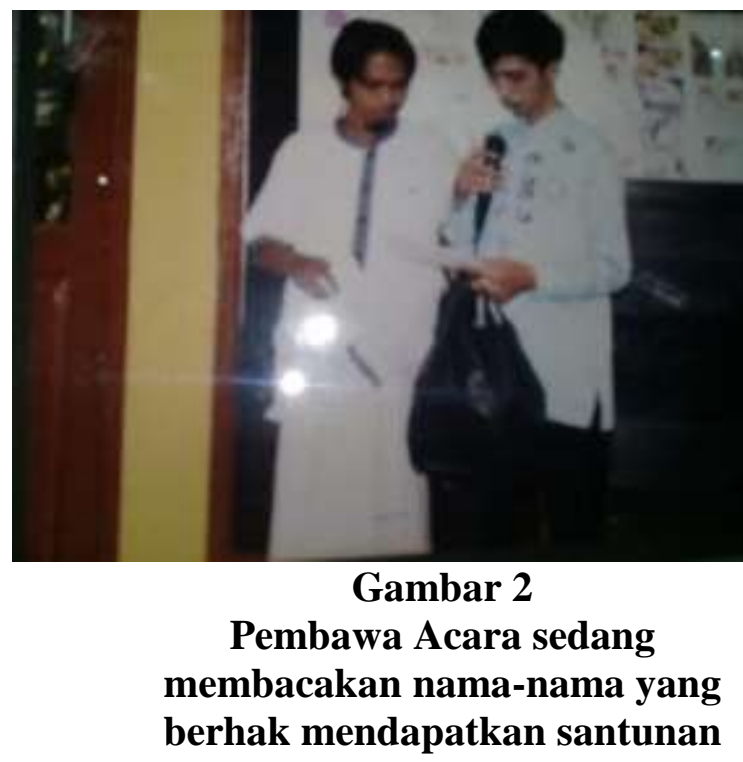




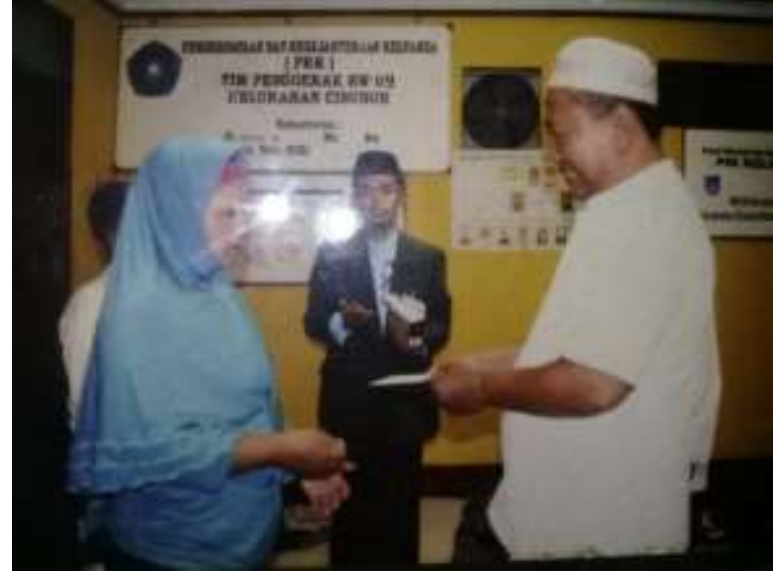

Gambar 3

Ketua Rt sedang memberikan santunan kepada dhu'afa

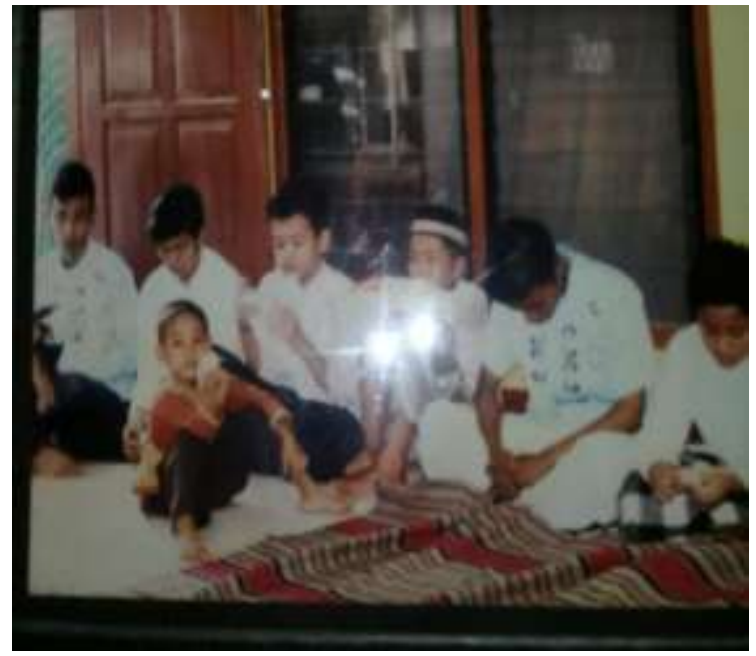

Gambar 4

Yatim Piatu sedang mendengarkan ceramah tentang fadilah berbagi kepada yang membutuhkan

\section{SIMPULAN}

Setelah penulis melakukan penelitian ini, dengan cara menerapkan akhlaq dan memberikan santunan kepada Yatim Piatu dan Dhu'afa di wilayah majlis ta'lim al munawwarah cibubur. Penulis mendapatkan banyak manfaat, baik itu pengalaman, pengetahuan dan semua yang terkait dalam kegiatan tersebut. Dan masyarakat di wilayah majlis ta'lim almunawwarah cibubur sangat antusias dan mendukung kegiatan itu. Sehingga penulis menjadi semangat memberikan materi dan melakukan kegiatan berbagi kepada yatim piatu dan dhu'afa.

Dengan adanya kerjasama yang baik antara penulis dan masyarakat lingkungan, maka memberikan hasil yang baik. Remaja memiliki Akhlaq dan memiliki rasa untuk berbagi kepada mereka yang yatim piatu dan dhu'afa. Dan para remaja memiliki tujuan untuk wilayah majlis ta'lim al munawwarah, agar akhlaq yang baik ini tidak terlepas dari diri mereka dan ingin mengadakan santunan atau berbagi kepada yatim piatu dan dhua'afa setiap Bulan Ramadhan.

Semoga dengan ada nya penelitian ini, penulis dapat menghasilkan karya ilmiah yang lain. Ramaja dapat mempertahankan kualitas akhlaq dan semangat dalam berbagi kepada yatim piatu dan dhu'afa.

\section{DAFTAR PUSTAKA}

[1] J-PAI: Jurnal Pendidikan Agama Islam, vol. 5 No. 2 januari - juni 2019, Homepage:http://ejournal.uinmalang.ac.id/index.php/jpai/

[2] Margono. Metodologi Penelitian Pendidikan. Jakarta: Penerbit Rineka Cipta. 2009.

[3] Masyuri. Zainuddin. Metodologi Penelitian. Bandung: Refika Aditama. 2011.

[4] E. Mulyana. Manajemen Pendidikan Karakter. Jakata: Bumi Aksara. 2013.

[5] http://kbbi.web.id/balai dan Depdiknas. Kamus Besar Indonesia. Jakarta: Indeks. 2007.

[6] Arifin, H.M. Hubungan Timbal balik Pendidikan Agama di lingkungan Sekolah dan orang tua Murid, Jakarta: Bulan bintang. 1990. 
[7] Departemen Agama. Al Qur'an dan Terjemah. Jakarta: UD Mekar Surabaya. 2010.

[8] Ardani, Moh, Al Qur'an dan Sufisme Mangku Negara IV. Yogyakarta: PT. Dana Bhakti Primayasa, 1998. 